\title{
Effects of cage-cleaning frequency on laboratory rat reproduction, cannibalism, and welfare
}

\author{
Charlotte C. Burn ${ }^{\mathrm{a}, *}$, Georgia J. Mason ${ }^{\mathrm{b}}$ \\ ${ }^{a}$ Department of Zoology, University of Oxford, South Parks Road, Oxford OX1 3PS, UK \\ ${ }^{\mathrm{b}}$ Department of Animal \& Poultry Science, University of Guelph, Ontario N1G 2W1, Canada
}

Accepted 4 February 2008

Available online 24 March 2008

\begin{abstract}
Regular cage-cleaning is important for health, but for breeding rats it disrupts the nest and removes olfactory signals important for parental care. To investigate how different cage-cleaning frequencies affect breeding rats' health and welfare, we monitored reproductive output, pup mortality, pup sex ratios, parental chromodacryorrhoea and in-cage ammonia levels for rats in a commercial breeding facility. Cages were cleaned twice-weekly, once-weekly or every 2 weeks (18 cages/group), replicated in two buildings, for the entire 36-week reproductive period. Frequent cage-cleaning had no clear benefits or major negative effects, showing no significant reductions in ammonia levels, or affects on health or overall pup mortality. However, frequent cage-cleaning slightly but significantly increased cannibalistic behaviour. This was because: (i) vulnerable 0-2-day-old pups were more likely to be exposed to a cage-cleaning event in the more frequent cage-cleaning regimes, physically disturbing them, and disrupting the nest and scent marks; and (ii) in the twice-weekly and weekly cleaned groups, pups under 2 days old at their first cage-cleaning were more likely to be cannibalised. Possible mechanisms behind these effects are discussed, including that cleaning might induce premature births, or stress the parents through noise or olfactory and physical disturbance. Finally, the cage-cleaning frequency producing most pups differed between the two buildings—an interactive effect corroborating previous findings that same-strain rodents' phenotypes can differ with environment. Overall, we suggest that for breeding rats, cage-cleaning regimes should minimise noise, dissemination of unfamiliar conspecific odours, and physical disturbance during very late pregnancy and the first few days following birth.
\end{abstract}

(C) 2008 Elsevier B.V. All rights reserved.

Keywords: Animal welfare; Husbandry; Hygiene; Cannibalism; Reproduction; Rodents

* Corresponding author at: School of Clinical Veterinary Science, University of Bristol, Langford House, Bristol BS40 5DU, UK.

E-mail address: charlotte.burn@worcester.oxon.org (C.C. Burn). 


\section{Introduction}

Cleaning of animals' cages or enclosures is necessary for almost all captive animals, whether they are kept in laboratories, farms, or zoos, or as pets, to prevent waste products accumulating to harmful or aversive levels. More frequent cleaning of rodent cages can reduce ammonia levels (Carissimi et al., 2000; Reeb-Whitaker et al., 2001; Burn et al., 2006a) and microbial counts (Borrello et al., 1998), and increase rodent health (e.g. Cisar and Jayson, 1967; Van Winkle and Balk, 1986). However, cage-cleaning almost always involves temporary displacement of each animal, physical and olfactory disruption of the 'home' environment, and human contact, which could each cause stress. Cage-cleaning does indeed cause acute increases in arousal and possibly transient stress in diverse species including rhesus macaques (Line et al., 1989), mice (Gray and Hurst, 1995; but see Blom et al., 1993), hamsters (Conn et al., 1990; Gattermann and Weinandy, 1996), rats (Saibaba et al., 1996; Schnecko et al., 1998; Duke et al., 2001; Sharp et al., 2002; Burn et al., 2006b) and snakes (Chiszar et al., 1980).

Whether frequent cage-cleaning causes chronic or cumulative stress is far less certain. In mice, two studies found that cleaning mouse cages more frequently increased pup mortality (Chantry, 1964; Reeb-Whitaker et al., 2001). Breeding mice whose cages were cleaned more frequently also tended to have higher corticosterone concentrations (Reeb-Whitaker et al., 2001). Even merely disturbing breeding mice, by regularly lifting the cage-lid and inspecting the hidden individuals, caused a strong trend towards poorer breeding success (Peters et al., 2002).

In our own previous studies, we investigated whether frequent cage-cleaning affected the welfare of male experimental Wistar and Sprague-Dawley rats, and found little evidence that it is a cause for concern in those animals (Burn, 2006; Burn et al., 2006a,b). However, one small-scale study of breeding rats did find indications that cage-cleaning has long-term effects. That work involved six Osborne-Mendel females per treatment (Cisar and Jayson, 1967). More pups were successfully weaned, they weighed more, and fewer needed to be culled by the experimenters in the twice-weekly cage-cleaned group than those in the weekly cleaned group. However, cannibalism was more frequent in the twice-weekly cleaned group.

Our aim here was to investigate how cage-cleaning frequency affects the general health, welfare, and reproductive success of breeding rats and their pups on a large scale. Even if nonbreeding rats are little affected by frequent-cage-cleaning (Burn, 2006; Burn et al., 2006a,b), we were concerned that breeding rat populations could be more affected, for a number of reasons. Firstly, olfactory signals are very important in rat parental care. These include the pheromone, diodecyl proprionate, produced from the pup preputial gland to induce maternal licking (Brouettelahlou et al., 1991); odours produced by dams that prevent cohabiting males from killing pups (Mennella and Moltz, 1988), and that guide pups to the nipples (Porter and Winberg, 1999); and scents deposited in the bedding by the dams that reduce pup activity levels, keeping them in the nest (Porter and Winberg, 1999). Cage-cleaning could directly remove some of those signals (Mennella and Moltz, 1988; Porter and Winberg, 1999), and/or mask them with odours from human hands or gloves (including scents from previously handled rats). Furthermore, rodent cage-cleaning is accompanied by loud noise (Gamble, 1982; Voipio et al., 2006), physical displacement, human contact, and exposure to relatively bright light (Lane Petter, 1968; Busnel and Molin, 1978; Libbin and Person, 1979). It can also physically disrupt the nest structure, and involves transferring pups to a temporarily colder environment (e.g. Chantry, 1964; Lee and Williams, 1975). Acute physical stressors such as these could trigger neglect and/or cannibalism of pups (Lane Petter, 1968). In the longer-term, if frequent cage-cleaning causes chronic stress to 
the parents, this could also reduce their fertility (Boice, 1972), reduce pup birth weights and increase mortality rates (e.g. Cabrera et al., 1999).

Rats comprise $20 \%$ of all laboratory animals used in Europe (Commission of the European Communities, 2003) and about $14 \%$ of those in Canada (Canadian Council on Animal Care, 2001); thus any findings relevant to their health, welfare, and productivity would have implications for a large number of animals, in both commercial and research facilities. Here, we assessed the effects of twice-weekly, weekly and fortnightly cage-cleaning on the rats of a commercial breeding company (Harlan, Bicester, UK). We used outbred albino Wistars, chosen because they are one of the most commonly used stocks in the UK, and because they are pair-mated (rather than harem-mated), enabling us to follow the lifetime breeding performance of individual pairs. Because of the biosecurity requirements of the commercial establishment, all measurements (except chromodacryorrhoea) were carried out by the animals' normal technicians. Therefore, detailed behavioural observations were unfeasible, but measurements included as many rapidly observable aspects of rat health and welfare as possible.

\section{Materials and methods}

\subsection{Animals and housing}

The study animals were 108 pairs of Wistar (HsdBrlHan:WIST) rats, consisting of 54 pairs housed in each of two similar buildings ('A' and ' $\mathrm{B}$ ') maintained under commercial, barrier conditions. The cages were polypropylene $(51 \mathrm{~cm} \times 32 \mathrm{~cm} \times 20 \mathrm{~cm}, L \times W \times H)$ with a stainless steel mesh lid. Each cage contained autoclaved Lignocel 3-4 sawdust (J. Rettenmaier \& Söhne, Holzmühle, Germany), to a depth of about $2 \mathrm{~cm}$. They were provided with pelleted chow (2018S sterilisable, Harlan Teklad, Bicester, UK) ad libitum, and water was constantly available from an automatic system. The temperature and humidity were 19-21 ${ }^{\circ} \mathrm{C}$ and $55 \pm 1 \%$, respectively. The light:dark cycle was $12: 12 \mathrm{~h}$, with $2 \mathrm{~h}$ dawn and dusk periods (only half the lights were on).

In Building A there were approximately 6200 adult rats plus pre-weanling offspring (BN/SsN, LE and LH) and in Building B there were 6000 (all HsdBrlHan:WIST). Obvious differences between the buildings were that the colony in A was populated in 2001 and all rats were kept in polypropylene cages, while B was populated in 2004 and rats outside the current study were kept in wire-bottomed cages. The individual staff also differed between the buildings. The study was staggered between the two buildings, with Building A being 1 month ahead of Building B. Pairs were formed at 10 weeks of age. The experiment continued for the commercial lifetimes of the pairs, which is 9 months ( 36 weeks). Pups were weaned between 19 and 26 days of age (depending on their weight) at cage-cleaning, as is standard practice.

Within each building, cages were allocated to the following cage-cleaning regimes: twice-weekly, once-weekly, or every 2 weeks - 'fortnightly' ( $n=18$ pairs per treatment in each building). Cages were cleaned by replacing the cage bases and bedding with fresh ones, but the cage lids were retained. Cage emptying was carried out manually on an unventilated table. The rats were always handled by the same technician. Due to the scale of the technicians' work in this commercial facility, randomising the positions of cages or the cleaning sequence proved to be logistically unmanageable, so cages were instead arranged within same-treatment racks. The tier-positions of cages within the racks, which are known to affect rat behaviour and physiology (e.g. Rao, 1991; Reinhardt, 2004; Izídio et al., 2005), were balanced across treatments, but the replication across the two buildings was especially worthwhile to help control for unknown rack effects.

The animals were cared for in accordance with the code of practice for the housing and care of animals in designated breeding and supplying establishments (Home Office, 1995), and was approved by the local ethical review process at the University of Oxford. 


\subsection{Data collection}

The breeding females (in Building A only) were weighed at the beginning and end of the study. Breeding parameters were measured, including the number of pups born in each litter, the number and sexes of the pups at each weaning, and for the first and third parity the body weights of one male and one female pup. The ages of the pups when cage-cleaning first occurred was noted for each litter. The rate of reproductive decline of the mothers was measured using the total number of litters they produced, and also as the ratio of the number of pups in their ninth litter (80\% of the pairs produced at least 9 litters) against the number in their second litter (the first one often being atypical). Adult and pup mortalities were noted, and the causes of pup death were recorded as 'stillborn', 'eaten by the parents', 'missing', 'found dead' or, in the case of cageflooding, 'wet'.

After 4 months in each building, ammonia concentrations were measured in each cage. A pump with Gastec glass measuring tubes with a range of 0.5-60 ppm were used (Anachem Ltd., Bedfordshire, UK). These were inserted in through the door in the top of the cage, and the measurements were taken in the centre of the cage just above the sawdust. Measurements were taken on the day before all cages were cleaned, so the fortnightly cleaned cages had 13 days of soiling, contrasting with the twice-weekly cleaned ones, which had only 2-3 days of soiling.

Both parents' noses were scored for chromodacryorrhoea - 'red/bloody tears', a Harderian gland secretion that increases in a variety of aversive situations in rats (Harkness and Ridgway, 1980; Mason et al., 2004; Burn, 2006) - by an experienced experimenter, wearing a powered respirator due to rodent allergy. This took place 8 months into the project because older rats produce more chromodacryorrhoea than young ones (Harkness and Ridgway, 1980), and hence the secretion is more visible. Scoring was carried out in Building B alone, because it was not possible to enter both buildings within the necessary timescale due to potential disease transfer (particularly since the respirator could not be completely sterilised). The observer tapped gently with a pen on the front of each cage to encourage the rats to present their noses for inspection. The method used for scoring was on a 6-point scale (0-5), as described elsewhere (Burn et al., 2006a,b). Chromodacryorrhoea measurements were taken the morning before cage-cleaning, when the soiling of the different cages was at its most contrasting, and again at the same time on the day of cleaning (about $2 \mathrm{~h}$ after cagecleaning).

\subsection{Statistical analysis}

For the lifetime breeding parameters and ammonia measurements, general linear models (GLMs) were used, with cage-cleaning frequency and building, and their interactions as fixed factors. For the pup weights from the first and third litters, the sex of the pups and their cage (a random factor, nested in cage-cleaning frequency and building) were also included. For chromodacryorrhoea, the cage, the order in which cages were observed, and whether the measurement was taken before or after cleaning were included alongside cleaning frequency, and their interactions. Data were square-root, log, or arcsine square-root transformed as necessary, and the model residuals were inspected graphically to verify whether they met the assumptions of the model. For those variables that did not meet the assumptions of GLMs, logistic regressions were used. Models were improved by removing redundant non-significant interactions. The statistical program used was Minitab ${ }^{\mathrm{TM}}$ Version 14 (Minitab Ltd., Pennsylvania, USA).

To assess effects on cannibalism, pups that were known to have been cannibalised, which is rarely witnessed directly, and those who were noted as 'missing', were combined into a single category (similar to Mohan, 1974). The effect of the age of the pups at their first cage-cleaning on the likelihood of cannibalism was analysed using a Generalized Linear Mixed Model (glmmPQL, MASS library, R freeware, Version 2.4); cannibalism was the binary response, and the treatment group, mean age at first cage-cleaning, mean litter size, and their interactions were the predictors. Cage (nested within the treatment group) was included as a random factor. 


\section{Results}

Cage-cleaning frequency had no significant main effects except that more pups were cannibalised when cages were cleaned more frequently (Fig. 1). Other recorded mortalities did not show this pattern. More frequent cleaning increased cannibalism in terms of both how many pups were eaten or missing $(z=2.15 ; n=106 ; P=0.032)$ and the percentage of pairs that did or did not eat or miss pups $(z=2.06 ; n=106 ; P=0.039)$. An interaction between age at first cagecleaning and the treatment group meant that, in the twice-weekly and, to a lesser extent, the onceweekly cleaning treatments cannibalism was more likely to occur if cages were cleaned sooner after birth (i.e. when the pups were younger), but this was not observed in the fortnightly treatment ( $t=2.85$, d.f. $=882$, with 106 clusters, $P=0.005)$ (Fig. 2 ). The absolute percentage of pups that were cannibalised was only $2.60 \pm 0.04 \%$ of all pups born, but at least one pup was cannibalised from $10.9 \%$ of litters. Also, cannibalism was the largest recorded type of pup mortality (stillborns: $0.38 \%$ of pups born; individuals found dead: $0.77 \%$; and deaths from cageflooding: $0.76 \%$ ). The weaning weights of surviving pups from litters that had included some cannibalised pups did not differ significantly from other pup weights.
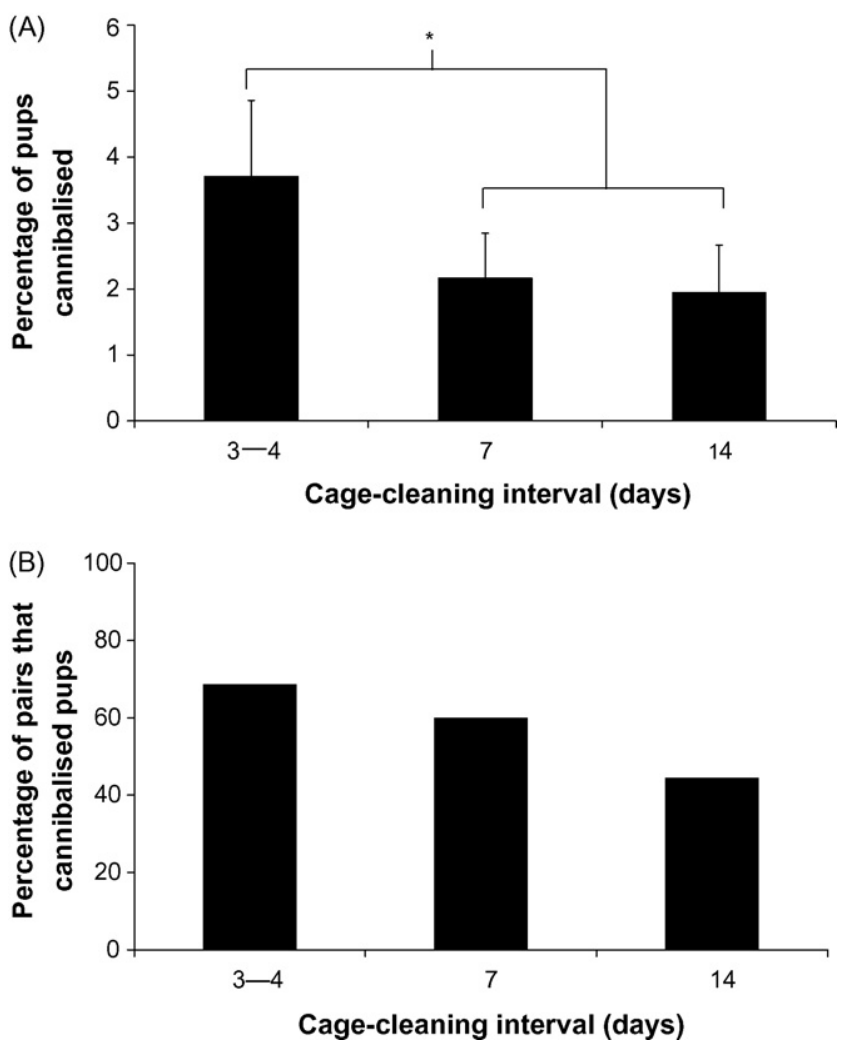

Fig. 1. The effect of cage-cleaning frequency on cannibalism of pups. More frequent cleaning increased (A) the mean ( \pm S.E.) proportion of pups that were cannibalised in the two buildings, and (B) the percentage of parents that cannibalised pups at some stage during the project. *Indicates the pairwise significant difference $(P<0.05)$ on graph A, but in graph B it was the covariate trend across cleaning intervals that was significant. 


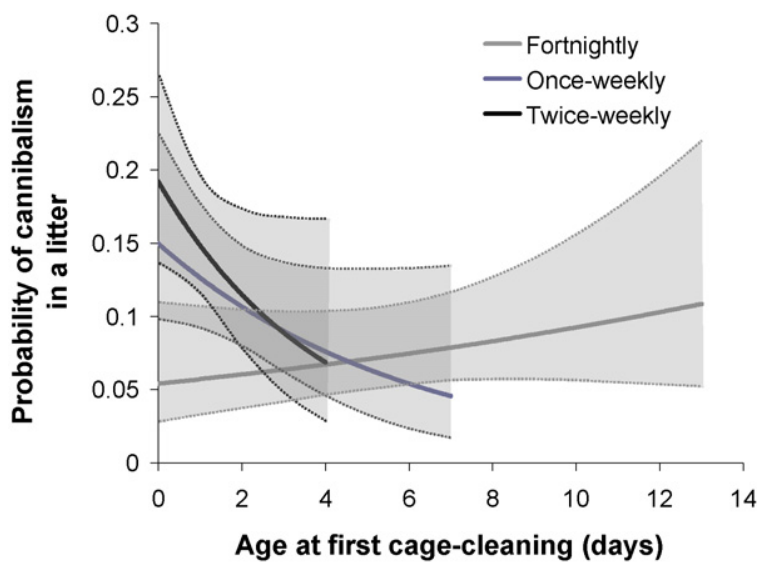

Fig. 2. The relationship between the age of the litters when their cages were first cleaned and the likelihood of cannibalism. The fitted lines and shaded $95 \%$ confidence intervals show that for the twice-weekly, and to a lesser extent the once-weekly, cleaning group cannibalism was more likely if cage-cleaning occurred earlier in life. There was no significant trend in the fortnightly cleaned group. Note that the day of cleaning might not necessarily have been the day the pups were cannibalised; data on when the cannibalism occurred were not available, so the pups may have been eaten at a later date.

Cage-cleaning frequency had no other main effects, not even on ammonia concentrations (twice-weekly mean \pm S.E.: $13.5 \pm 0.5$ versus fortnightly: $13.9 \pm 0.6 ; P=0.642$ ). However, it interacted with the building the rats were housed in (Fig. 3): the fortnightly cleaning group had the fewest pups born and weaned in Building A, but in Building B the most were born and weaned in that treatment group (number born: $F_{2,100}=4.47 ; P=0.014$; number weaned: $F_{2,100}=4.30$; $P=0.016)$. This effect was also apparent for the mean litter sizes, with rats in fortnightly cleaned cages having the smallest litters in Building $\mathrm{A}$, and the largest in Building $\mathrm{B}\left(F_{2,100}=7.86\right.$; $P=0.001$ ) (Fig. 3).

Significantly more births were recorded on the cage-cleaning day itself, compared with noncleaning days $\left(F_{1,107}=37.79 ; P<0.001\right)$ (Fig. 4$)$. Thus, births on the day of cage-cleaning appeared around twice as likely as expected by chance, in the weekly and fortnightly cleaning groups. For the fortnightly cleaning treatment, Fig. 4 suggests that births also peaked 1 week after cleaning.

Building also had a significant main effect (Table 1) on every variable tested, except for the pup sex ratios and mortality from cannibalism or stillbirths (parental chromodacryorrhoea and maternal weight were only tested in one building). In Building A more pups were born and weaned and there were more litters in total, but each pup was lighter than in Building B and a higher proportion of them were found dead. The weight difference between male and female pups (males being heavier) was significantly more pronounced in Building B than in A for the first litters.

\section{Discussion}

We investigated whether cage-cleaning frequency affected the reproductive performance and welfare of breeding rats. Overall, we found no significant main effects of cleaning frequency on any health and fertility measures (mortality rates and numbers of pups born and weaned), on other indices sensitive to stress (chromodacryorrhoea, maternal reproductive decline and weight 

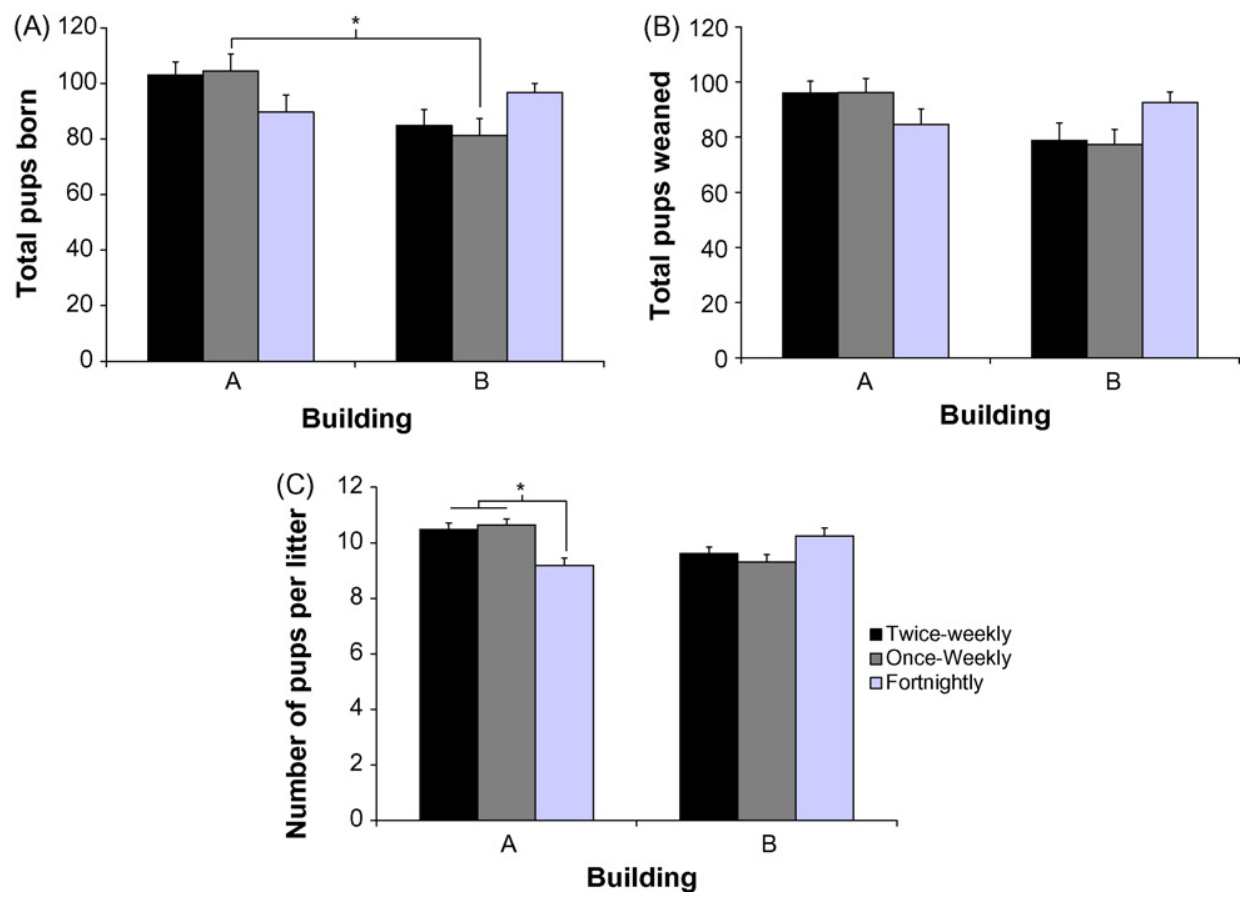

Fig. 3. The mean (S.E.) lifetime number of pups (A) born and (B) weaned, and (C) the litter size for breeding pairs cage-cleaned at different frequencies in two different buildings. The fortnightly cage-cleaning decreased the number of offspring compared with more frequent cage-cleaning in Building A, but it increased the number of offspring in Building B.

Table 1

Significant differences between the two buildings

\begin{tabular}{|c|c|c|c|c|}
\hline Variable & Statistical values & $\begin{array}{l}\text { Building A } \\
\text { (mean } \pm \text { S.E.) }\end{array}$ & $\begin{array}{l}\text { Building B } \\
\text { (mean } \pm \text { S.E.) }\end{array}$ & $\begin{array}{l}\text { Effect } \\
\text { direction }\end{array}$ \\
\hline Number born per pair & $F_{1,100}=6.40 ; P=0.013$ & $98.9 \pm 3.4$ & $87.6 \pm 3.0$ & $\mathrm{~A}>\mathrm{B}$ \\
\hline Number weaned per pair & $F_{1,100}=4.70 ; P=0.032$ & $92.1 \pm 3.0$ & $82.9 \pm 3.1$ & $\mathrm{~A}>\mathrm{B}$ \\
\hline Number of litters per pair & $\begin{array}{l}\text { Odds }=3.59 ; z=3.39 \\
n=106 ; P=0.001\end{array}$ & $9.9 \pm 0.2$ & $9.0 \pm 0.3$ & $\mathrm{~A}>\mathrm{B}$ \\
\hline Number found dead per pair & $\begin{array}{l}\text { Odds }=5.41 ; z=2.10 \\
n=106 ; P=0.036\end{array}$ & $1.3 \pm 0.4$ & $0.4 \pm 0.3$ & $\mathrm{~A}>\mathrm{B}$ \\
\hline 1st litter pup weight (g) & $F_{1,96}=19.77 ; P<0.001$ & $40.9 \pm 1.0$ & $47.3 \pm 0.9$ & $\mathrm{~B}>\mathrm{A}$ \\
\hline 3rd litter pup weight (g) & $F_{1,95}=16.97 ; P<0.001$ & $39.8 \pm 1.3$ & $46.9 \pm 1.3$ & $\mathrm{~B}>\mathrm{A}$ \\
\hline $\begin{array}{l}\text { 1st litter male-female } \\
\text { weight difference }(\mathrm{g})\end{array}$ & $F_{1,96}=6.02 ; P=0.016$ & $0.51 \pm 0.50$ & $2.09 \pm 0.40$ & $\mathrm{~B}>\mathrm{A}$ \\
\hline Ammonia (ppm) & $F_{1,101}=273.33 ; P<0.001$ & $10.9 \pm 0.3$ & $16.5 \pm 0.2$ & $\mathrm{~B}>\mathrm{A}$ \\
\hline
\end{tabular}

The statistics used were either GLMs (where an $F$-value is given), or for non-parametric data, ordinal logistic regressions (where a $z$-value is given). In Building A, significantly more pups were born and weaned, and there were more litters in total, but pups were lighter and more frequently found dead than in Building B. Ammonia concentrations were low in both buildings, but were higher in B than in A. Maternal weight and parental chromodacryorrhoea could not be compared between the buildings because measurements were only possible in one building. 

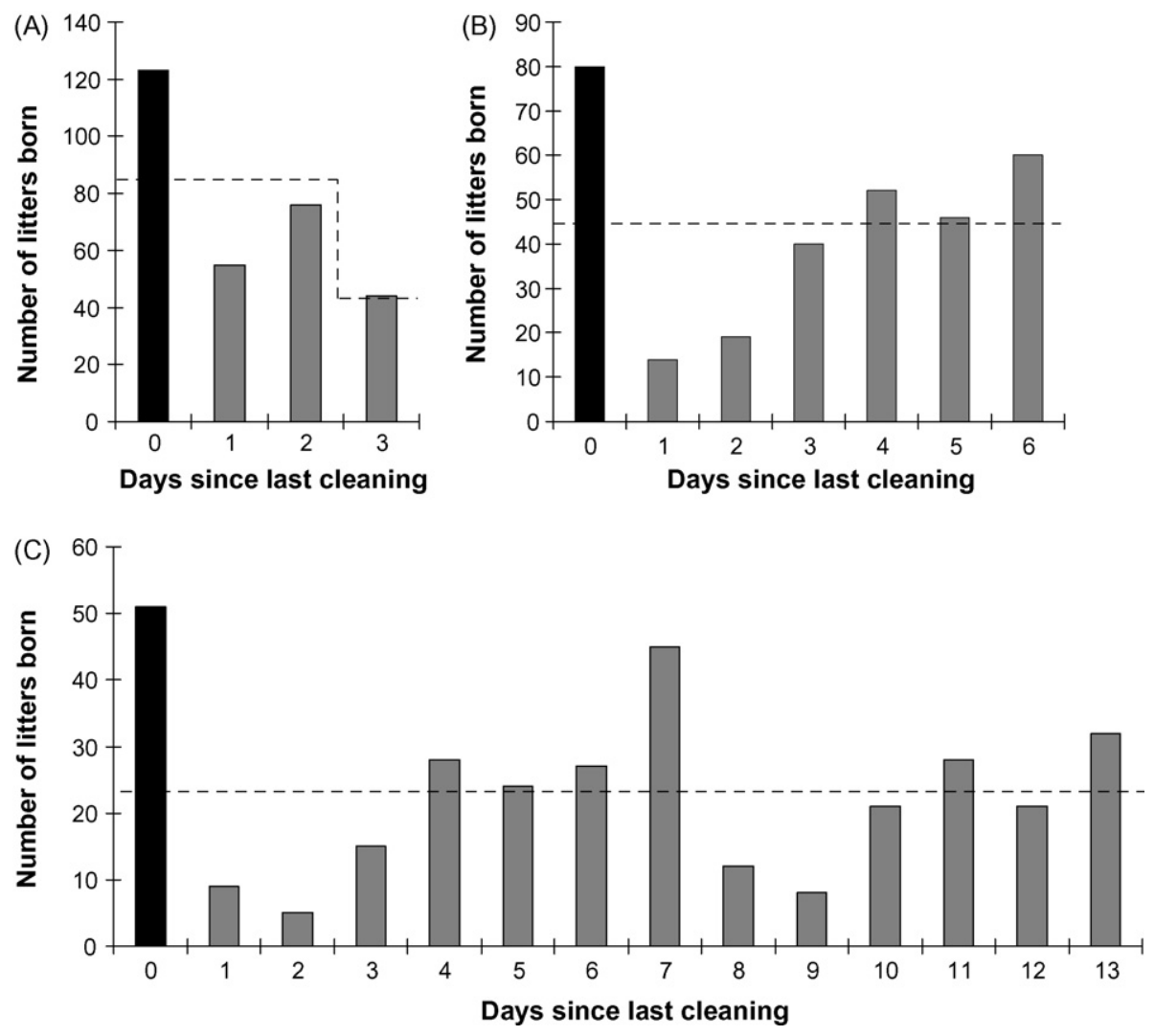

Fig. 4. The numbers of pups born on each day of the (A) twice-weekly, (B) weekly and (C) fortnightly cage-cleaning cycle. The cage-cleaning day, Day 0 , is highlighted in black. The dotted lines show the numbers of pups expected by chance if they were distributed evenly across days. For the twice-weekly group there is a step in probability, because half the cleaning events occurred on Day 2 of the cycle (Fridays) and half on Day 3 (Tuesdays), so pups had 50\% less chance of being born on Day 3 than any other day. In general more births were recorded on the cage-cleaning day itself than on other days, but the fortnightly cleaning group also suggests a peak midway through the cleaning cycle, on the day when all neighbouring cages would have been cleaned.

gain, and pup sex ratio), or on ammonia levels. Furthermore, in a follow-up study, we found no significant effects on pup handleability or anxiety profiles in adulthood (Burn et al., 2008).

However, we found that cannibalism increased with more frequent cage-cleaning, which is consistent with the small-scale study by Cisar and Jayson (1967), and with common perception (e.g. Home Office, 1995; Hansen et al., 2000). Cannibalism was rare, affecting about $2.6 \%$ of all the pups born, which is approximately consistent with previous studies (Chantry, 1964; Reynolds, 1981; DeSantis and Schmaltz, 1984), so cleaning frequency had no significant effect on pup mortality generally. Nevertheless, under these clean conditions and with this outbred strain, other causes of mortality were even rarer. Therefore, on a large scale or with more susceptible rat strains, reducing cannibalism might lead to significant increases in the numbers of pups weaned.

Cannibalistic behaviour is not a uniform phenomenon (Elwood, 1991); it can sometimes be a response to pups that are already dead or dying, and other times be a by-product of direct infanticide, which in turn can be a response to various different situations (Fox, 1975; DeSantis 
and Schmaltz, 1984). Here we found no indication that it occurred as a result of poor maternal health or welfare (Boice, 1972), since cage-cleaning frequency had no significant effects on maternal chromodacryorrhoea, weight gain, rate of reproductive decline, or litter sex ratios. Cage-cleaning also did not seem to affect litter size, so the increased cannibalism in the more frequent cage-cleaning groups was not a response to larger litters (Day and Galef, 1977; Gandelman and Simon, 1978).

It is possible that cannibalism was a response to a higher proportion of weak pups in the more frequent cleaning groups; for example, if the cleaning process itself triggered birth (Fig. 4), this could have resulted in a higher proportion of premature litters. Alternatively, (or in addition) frequent cage-cleaning might have increased cannibalism through more frequent olfactory (e.g. Mennella and Moltz, 1988; Moles et al., 2004) auditory, and/or physical (Lane Petter, 1968; Busnel and Molin, 1978) disturbances, or nest disruption and cooling (e.g. Chantry, 1964; Lee and Williams, 1975) at a time when pups were vulnerable. Noise certainly reaches a peak during cleaning and is a stressor (Gamble, 1982; Voipio et al., 2006), so cleaning cages as quietly as possible around breeding rats could help prevent cannibalism (Lane Petter, 1968; Busnel and Molin, 1978). Cage-cleaning in an unventilated area of the stock room also increases airborne levels of rodent urinary proteins (Thulin et al., 2002), potentially disseminating unfamiliar conspecific odours between cages - since unfamiliar male odours are known to stress mother rats (Moles et al., 2004), this olfactory disturbance should be avoided where possible. Fig. 2 shows that, in more frequently cleaned cages, cannibalism was more likely to occur if cagecleaning occurred on the day of birth (consistent with cannibalism of prematurely born pups), or during the first 2 days following it (consistent with cannibalism when cages containing very young pups are disturbed). Note that we had no information on when cannibalism events occurred, so even though cage-cleaning affected them, they were not necessarily on the same day as cage-cleaning.

In fact, the vast majority of cannibalism in rats has been reported to occur during the first week after birth, with some taking place in the second week, and virtually none in the third week (DeSantis and Schmaltz, 1984). Some rodent breeders already avoid cage-cleaning between birth and weaning (Libbin and Person, 1979), or at least within the first few days of birth (Peters et al., 2002), specifically to prevent cannibalism and neglect by the parents. Our data suggest that for twice-weekly and possibly once-weekly cleaning regimes this might be an effective way of reducing cannibalism (Fig. 2).

Overall, cage-cleaning frequency affected the mean litter size, and correspondingly the numbers of pups born and weaned, but the effect depended on the building the pups were born and raised in: fortnightly cage-cleaning was associated with the greatest number of pups in one building and the fewest in the other. These interactions between cage-cleaning frequency and building imply that if we had only carried out our study in Building A, we would have concluded that fortnightly cage-cleaning reduces the numbers of pups, while we would have concluded the opposite had we only used Building B. This could have been due to differences between the cage racks, the different humans working in the buildings, olfactory or vocal communications within the different animal populations, or any number of environmental differences. This supports and extends the finding that rats of the same strain differ between different breeding companies (Rex et al., 1996; Germann et al., 1998); here they differed within the same breeding company. Therefore, in agreement with previous studies (e.g. Crabbe et al., 1999; Wurbel, 2000; Wahlsten et al., 2003; Garner et al., 2006), our findings reveal difficulties regarding the feasibility of standardisation between different experiments, and reaffirm the merits of replicating research under different conditions. 
Unlike Cisar and Jayson (1967), we did not find that overall weaning success was increased by more frequent cage-cleaning. This might be explained by the relative contribution of hygiene to pup survival in the two studies. In Cisar and Jayson's study, rats were kept in a conventional animal unit in the 1960s, when around $97.5 \%$ of pup mortality in similar units was due to diseases (Porter, 1968). Therefore, frequent cage-cleaning might have been essential for preventing disease. In contrast, our study animals were kept in a barrier unit, in which there were no detected pathogens (Harlan's Health Monitoring reports, 2005, unpublished) and ammonia levels were almost certainly lower (Table 1, cf. Perkins and Lipman, 1995; Carissimi et al., 2000).

Here, the cage-cleaning days themselves were associated with more births than non-cleaning days. This may have been an artefact of the way that births were recorded: pup births and ages were usually recorded and estimated during cage-cleaning, so very young pups might have been recorded as being born that day unless it was obvious that they were several days old. However, the opinions of the staff involved differed over whether this recording artefact would occur or not, so other explanations require consideration. Also, a recording artefact would not fully explain the peak in births midway through the cleaning cycle in the fortnightly treatment. An alternative explanation could be that the noise (Lane Petter, 1968; Busnel and Molin, 1978), circulation of conspecific odours (Moles et al., 2004), or physical disturbance associated with cleaning, even of neighbouring cages, triggered births perhaps through stress or increased activity in the mother. Physical strain, and chronic and acute stress, can shorten gestational duration under some circumstances in humans (Glynn et al., 2001; Hobel and Culhane, 2003) and domestic animals (Silver, 1990), but the effects are little understood, and differ between species. The midway peak in the fortnightly treatment also suggests that we may not have entirely effectively simulated the fortnightly cleaning rate, when all cages in a room would be cleaned fortnightly.

Apart from cage-cleaning effects, most variables differed between the two buildings. Interestingly, the differences between the buildings corresponded to the pattern of reproductive trade-offs predicted by theory, in that offspring 'quality' is balanced against the number of offspring produced (Smith and Fretwell, 1974). Building A produced more offspring (in terms of numbers born, weaned and the number of litters), but each individual pup weighed less, sexual dimorphism was reduced, and pup mortalities were higher than in Building B.

\section{Conclusion}

Here and in a follow-up study (Burn et al., 2008), we found no clear benefits of frequent cagecleaning to breeding rats, but it did increase the likelihood of cannibalism, and the cleaning process itself might have triggered parturition. We would therefore recommend that cages are not cleaned during the last few days of pregnancy (possibly avoiding premature induction of birth) or the first 2 days following birth (avoiding acute early disturbances). Also, more research is required about what aspects of cleaning trigger cannibalism, but until then, noise and the transfer of odours between cages are likely stressors, and should be kept to a minimum when cleaning the cages of breeding rats.

\section{Acknowledgements}

Many thanks to Alan Peters for his practical advice and expertise, and the staff at Harlan who made this study possible. Robert Campbell and Bill Browne are also gratefully acknowledged for their help with the GLMM and Fig. 2. This work was funded by the UK Home Office, on the recommendation of the Animal Procedures Committee. 


\section{References}

Blom, H.J.M., Witkam, A.C.P., Schlingmann, F., Hoogervorst, M.J.C., Van de Weerd, H.A., Baumans, V., Beynen, A.C., 1993. Demonstration of preference for clean versus soiled cages as expressed by laboratory mice. Unpublished Ph.D. Thesis. Utrecht University, Utrecht, The Netherlands.

Boice, R., 1972. Some behavioral tests of domestication in Norway rats. Behaviour 42, 198-231.

Borrello, P., D’Amore, E., Di Virgilio, A., Panzini, G., Valeri, M., Lorenzini, R.N., 1998. The use of AGI as a method to measure microbial contamination in the cage microenvironment. Anim. Technol. 49, 81-85.

Brouettelahlou, I., Amouroux, R., Chastrette, F., Cosnier, J., Stoffelsma, J., Vernetmaury, E., 1991. Dodecyl propionate, attractant from rat pup preputial gland-characterization and identification. J. Chem. Ecol. 17, 1343-1354.

Burn, C.C., 2006. Effects of husbandry manipulations and the laboratory environment on rat health and welfare. Unpublished D.Phil. Thesis. University of Oxford, Oxford, UK.

Burn, C.C., Day, M.J., Peters, A., Mason, G.J., 2006a. Long-term effects of cage-cleaning frequency and bedding type on laboratory rat health, welfare, and handleability: a cross-laboratory study. Lab. Anim. 40, 353-370.

Burn, C.C., Peters, A., Mason, G.J., 2006b. Acute effects of cage-cleaning at different frequencies on laboratory rat behaviour and welfare. Anim. Welf. 15, 161-172.

Burn, C.C., Deacon, R., Mason, G.J., 2008. Marked for life? Effects of early cage cleaning frequency, delivery batch and identification tail-marking on adult rat anxiety profiles. Dev. Psychobiol. 50, 266-277.

Busnel, M.C., Molin, D., 1978. Preliminary results of the effects of noise on gestating mice and their pups. In: Fletch, J.L., Busnel, R.G. (Eds.), Effects of Noise on Wildlife. Academic Press, New York, pp. 209-248.

Cabrera, R.J., Rodriguez-Echandia, E.L., Jatuff, A.S., Foscolo, M., 1999. Effects of prenatal exposure to a mild chronic variable stress on body weight, preweaning mortality and rat behavior. Braz. J. Med. Biol. Res. 32, 1229-1237.

Canadian Council on Animal Care, 2001. CCAC Animal Use Survey-2001. Retrieved July 2007, from http:// www.ccac.ca/en/Publications/Facts_Figures/pdfs/aus2001-all.pdf.

Carissimi, A.S., Chaguri, L.C.A.A., Teixeira, M.A., Mori, C.M.C., Macchione, M., Sant' Anna, E.T.G., Saldiva, P.H.N., Souza, N.L., Merusse, J.B.L., 2000. Effects of two ventilation systems and bedding change frequency on cage environmental factors in rats (Rattus norvegicus). Anim. Technol. 51, 161-170.

Chantry, D., 1964. The effects of handling and cage changing on breeding mice. J. Anim. Techn. Assoc. 15, 78-80.

Chiszar, D., Wellborn, S., Wand, M.A., Scudder, K.M., Smith, H.M., 1980. Investigatory behavior in snakes, 2: cage cleaning and the defecation in snakes. Anim. Learn. Behav. 8, 505-510.

Cisar, C.F., Jayson, G., 1967. Effects of frequency of cage cleaning on rat litters prior to weaning. Lab. Anim. Care 17, 215-217.

Commission of the European Communities, 2003. Third report from the Commission to the Council and the European Parliament on the statistics on the number of animals used for experimental and other scientific purposes in the member states of the European Union (No. COM/2003/0019). Commission of the European Communities, Brussels.

Conn, C.A., Borer, K.T., Kluger, M.J., 1990. Body temperature rhythm and response to pyrogen in exercising and sedentary hamsters. Med. Sci. Sports Exerc. 22, 636-642.

Crabbe, J.C., Wahlsten, D., Dudek, B.C., 1999. Genetics of mouse behavior: interactions with laboratory environment. Science 284, 1670-1672.

Day, C.S., Galef, B.G., 1977. Pup cannibalism: one aspect of maternal behavior in golden hamsters. J. Comp. Physiol. Psychol. 91, 1179-1189.

DeSantis, D.T., Schmaltz, L.W., 1984. The mother-litter relationship in developmental rat studies: cannibalism vs. caring. Dev. Psychobiol. 17, 255-262.

Duke, J., Zammit, T., Lawson, D., 2001. The effects of routine cage-cleaning on cardiovascular and behavioural parameters in male Sprague-Dawley rats. Contemp. Top. Lab. Anim. Sci. 40, 17-20.

Elwood, R.W., 1991. Ethical implications of studies on infanticide and maternal aggression in rodents. Anim. Behav. 42, 841-849.

Fox, L.R., 1975. Cannibalism in natural populations. Annu. Rev. Ecol. Syst. 6, 87-106.

Gamble, M.R., 1982. Noise and laboratory animals. J. Inst. Anim. Techn. 33, 5-15.

Gandelman, R., Simon, N.G., 1978. Spontaneous pup-killing by mice in response to large litters. Dev. Psychobiol. 11, 235-241.

Garner, J.P., Thogerson, C.M., Mench, J.A., Würbel, H. 2006. Standardization and the Red Queen: applying methodologies from ethology, neuropsychology, and field biology to problems in high-throughput behavioral methods, Paper presented at the Proceedings of the 40th International Congress of the ISAE, Bristol.

Gattermann, R., Weinandy, R., 1996. Time of day and stress response to different stressors in experimental animals. Part I: Golden hamster (Mesocricetus auratus Waterhouse, 1839). J. Exp. Anim. Sci. 38, 66-76. 
Germann, P.G., Hafner, D., Hanauer, G., Drommer, W., 1998. Incidence and severity of granulomatous pneumonia in Brown Norway rats: breeder related variations. J. Exp. Anim. Sci. 39, 22-33.

Glynn, L.M., Wadhwa, P.D., Dunkel-Schetter, C., Chicz-DeMet, A., Sandman, C.A., 2001. When stress happens matters: effects of earthquake timing on stress responsivity in pregnancy. Am. J. Obstet. Gynecol. 184, 637-642.

Gray, S., Hurst, J.L., 1995. The effect of cage cleaning on aggression within groups of male laboratory mice. Anim. Behav. 49, 821-826.

Hansen, A.K., Baumans, V., Elliott, H., Francis, R., Holgate, B., Hubrecht, R., Jennings, M., Peters, A., Stauffacher, M., 2000. Future principles for housing and care of laboratory rodents and rabbits (second meeting). Report of the Working Party for the Preparation of the Fourth Multilateral Consultation of Parties to the European Convention for the Protection of Vertebrate Animals used for Experimental and Other Scientific Purposes, Strasbourg.

Harkness, J.E., Ridgway, M.D., 1980. Chromodacryorrhea in laboratory rats (Rattus norvegicus): etiologic considerations. Lab. Anim. Sci. 30, 841-844.

Hobel, C., Culhane, J., 2003. Role of psychosocial and nutritional stress on poor pregnancy outcome. J. Nutr. 133, 1709S$1717 \mathrm{~S}$.

Home Office, 1995. Code of Practice for the Housing and Care of Animals in Designated Breeding and Supplying Establishments. Home Office, UK.

Izídio, G.S., Lopes, D.M., Spricigo Jr., L., Ramos, A., 2005. Common variations in the pretest environment influence genotypic comparisons in models of anxiety. Genes Brain Behav. 4, 412-419.

Lane Petter, W., 1968. Cannibalism in rats and mice. Proc. R. Soc. Med. 61, 1295-1296.

Lee, M.H.S., Williams, D.I., 1975. Long term changes in nest condition and pup grouping following handling of rat litters. Dev. Psychobiol. 8, 91-95.

Libbin, R.M., Person, P., 1979. Neonatal rat surgery: avoiding maternal cannibalism. Science 206, 66.

Line, S.W., Morgan, K.N., Markowitz, H., 1989. Heart rate and activity of rhesus monkeys in response to routine events. Lab. Primate Newsl. 28, 9-12.

Mason, G., Wilson, D., Hampton, C., Wurbel, H., 2004. Non-invasively assessing disturbance and stress in laboratory rats by scoring chromodacryorrhoea. Altern. Lab. Anim. 32, 153-159.

Mennella, J.A., Moltz, H., 1988. Infanticide in rats: male strategy and female counter-strategy. Physiol. Behav. 42, 19-28.

Mohan, C., 1974. Age-dependent cannibalism in a colony of albino rats. Lab. Anim. 8, 83-84.

Moles, A., Rizzi, R., D’Amato, F.R., 2004. Postnatal stress in mice: does stressing the mother have the same effect as stressing the pups? Dev. Psychobiol. 44, 230-237.

Perkins, S.E., Lipman, N.S., 1995. Characterization and quantification of microenvironmental contaminants in isolator cages with a variety of contact beddings. Contemp. Top. Lab. Anim. Sci. 34, 93-98.

Peters, A.G., Bywater, P.M., Festing, M.F.W., 2002. The effect of daily disturbance on the breeding performance of mice. Lab. Anim. 36, 188-192.

Porter, G., 1968. Pre-weaning loss of laboratory animals. Proc. R. Soc. Med. 61, 1295.

Porter, R.H., Winberg, J., 1999. Unique salience of maternal breast odors for newborn infants. Neurosci. Biobehav. Rev. 23, 439-449.

Rao, G.N., 1991. Light intensity-associated eye lesions of Fischer-344 rats in long-term studies. Toxicol. Pathol. 19, 148155.

Reeb-Whitaker, C.K., Paigen, B., Beamer, W.G., Bronson, R.T., Churchill, G.A., Schweitzer, I.B., Myers, D.D., 2001. The impact of reduced frequency of cage changes on the health of mice housed in ventilated cages. Lab. Anim. 35, 58-73.

Reinhardt, V., 2004. Common husbandry-related variables in biomedical research with animals. Lab. Anim. 38, $213-235$.

Rex, A., Sondern, U., Voigt, J.P., Franck, S., Fink, H., 1996. Strain differences in fear-motivated behavior of rats. Pharmacol. Biochem. Behav. 54, 107-111.

Reynolds, R.D., 1981. Preventing maternal cannibalism in rats. Science 213, 1146.

Saibaba, P., Sales, G.D., Stodulski, G., Hau, J., 1996. Behaviour of rats in their home cages: daytime variations and effects of routine husbandry procedures analysed by time sampling techniques. Lab. Anim. 30, 13-21.

Schnecko, A., Witte, K., Lemmer, B., 1998. Effects of routine procedures on cardiovascular parameters of SpragueDawley rats in periods of activity and rest. J. Exp. Anim. Sci. 38, 181-190.

Sharp, J.L., Zammit, T.G., Azar, T.A., Lawson, D.M., 2002. Stress-like responses to common procedures in male rats housed alone or with other rats. Contemp. Top. Lab. Anim. Sci. 41, 8-14.

Silver, M., 1990. Prenatal maturation, the timing of birth and how it may be regulated in domestic animals. Exp. Physiol. $75,285-307$.

Smith, C.C., Fretwell, S.D., 1974. Optimal balance between size and number of offspring. Am. Nat. 108, $499-506$.

Thulin, H., Bjorkdahl, M., Karlsson, A.-S., Renstrom, A., 2002. Reduction of exposure to laboratory animal allergens in a research laboratory. Ann. Occup. Hyg. 46, 61-68. 
Van Winkle, T.J., Balk, M.W., 1986. Spontaneous corneal opacities in laboratory mice. Lab. Anim. Sci. 36, $248-255$. Voipio, H.M., Nevalainen, T., Halonen, P., Hakumäki, M., Björk, E., 2006. Role of cage material, working style and hearing sensitivity in perception of animal care noise. Lab. Anim. 40, 400-409.

Wahlsten, D., Metten, P., Phillips, T.J., Boehm, S.L., Burkhart-Kasch, S., Dorow, J., Doerksen, S., Downing, C., Fogarty, J., Rodd-Henricks, K., Hen, R., McKinnon, C.S., Merrill, C.M., Nolte, C., Schalomon, M., Schlumbohm, J.P., Sibert, J.R., Wenger, C.D., Dudek, B.C., Crabbe, J.C., 2003. Different data from different labs: lessons from studies of geneenvironment interaction. J. Neurobiol. 54, 283-311.

Wurbel, H., 2000. Behaviour and the standardization fallacy. Nat. Genet. 26, 263. 